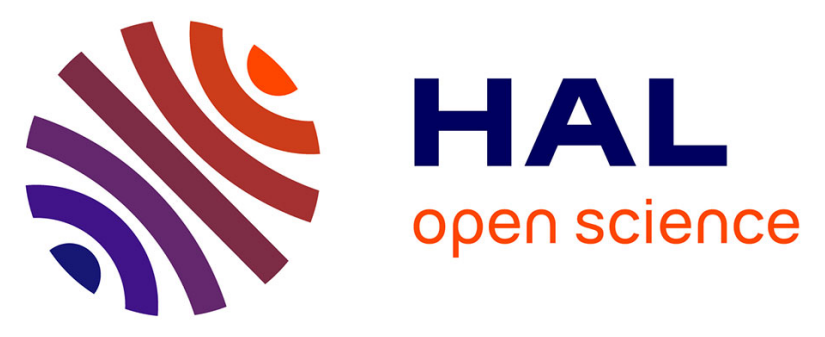

\title{
Pre-surgical study of the biological effects of the selective cyclo-oxygenase-2 inhibitor celecoxib in patients with primary breast cancer
}

Lesley-Ann Martin, Giles L. S. Davies, Marion T. Weigel, Nadine Betambeau, Margaret J. Hills, Janine Salter, Geraldine Walsh, Roger A’Hern, Mitch

Dowsett

\section{To cite this version:}

Lesley-Ann Martin, Giles L. S. Davies, Marion T. Weigel, Nadine Betambeau, Margaret J. Hills, et al.. Pre-surgical study of the biological effects of the selective cyclo-oxygenase-2 inhibitor celecoxib in patients with primary breast cancer. Breast Cancer Research and Treatment, 2010, 123 (3), pp.829836. 10.1007/s10549-010-1100-z . hal-00564774

\section{HAL Id: hal-00564774 \\ https://hal.science/hal-00564774}

Submitted on 10 Feb 2011

HAL is a multi-disciplinary open access archive for the deposit and dissemination of scientific research documents, whether they are published or not. The documents may come from teaching and research institutions in France or abroad, or from public or private research centers.
L'archive ouverte pluridisciplinaire HAL, est destinée au dépôt et à la diffusion de documents scientifiques de niveau recherche, publiés ou non, émanant des établissements d'enseignement et de recherche français ou étrangers, des laboratoires publics ou privés. 
Pre-surgical study of the biological effects of the selective cyclo-oxygenase- 2 inhibitor celecoxib in patients with primary breast cancer

${ }^{1{ }^{*}}$ Lesley-Ann Martin, ${ }^{2 \S}$ Giles L.S Davies, ${ }^{1}$ Marion T Weigel, ${ }^{2}$ Nadine Betambeau, ${ }^{2}$ Margaret J Hills, ${ }^{2}$ Janine Salter, ${ }^{3}$ Geraldine Walsh, ${ }^{2}$ Roger A'Hern and ${ }^{1},{ }^{2}$ Mitch Dowsett, ${ }^{1}$ Breakthrough Breast Cancer Research Centre, Institute of Cancer Research, Fulham Rd, London SW3 6JB UK, ${ }^{2}$ Dept Academic Biochemistry, Royal Marsden Hospital, Fulham Rd, London SW3 6JJ UK. ${ }^{3}$ Dept of Medicine Breast Unit, The Royal Marsden Hospital, Fulham Rd, London SW3 6JJ UK.

Running Title: Pre-surgical study of celecoxib in primary breast cancer

$\S$ These authors contributed equally to this manuscript

*To whom correspondence should be addressed.

Lesley-Ann.Martin@icr.ac.uk

Key words. Estrogen receptor, COX2, celecoxib, pre-surgical study, Ki67

Abstract 
Purpose: Cyclooxygenase $2(\mathrm{COX}-2)$ is implicated in the regulation of aromatase transcription in malignant breast tissue and has been considered as a potential target for tissue specific aromatase suppression. We initiated a randomised controlled pre-surgical study of celecoxib versus no treatment in women with primary breast cancer to determine the effects of COX-2 inhibition on markers of biological response.

Methods: Postmenopausal women (50-80 years of age) with stage I or II, primary breast cancer, were randomised 2:1 to receive $400 \mathrm{mg}$ /day celecoxib or no treatment for 14 days prior to surgery. A core biopsy was obtained pre- and post- treatment. Paired baseline and endpoint biopsies were analyzed for Ki67, apoptosis, COX2, CD31, estrogen receptor (ER) and progesterone receptor $(\mathrm{PgR})$. Comparisons between the treatment groups were conducted using the Mann Whitney test with a two sided 5\% significance.

Results: Of the 25 patients treated, 23 had evaluable data and 19 (83\%) were ER-positive. Overall the geometric mean change in Ki67, the primary end point, relative to baseline in the celecoxib arm was $-16.6 \%(\mathrm{p}=0.056)$. The change in the no treatment group was $-8.1 \%$ $(\mathrm{p}=0.24)$. There was no statistically significant difference in the change between the 2 groups. Celecoxib did not significantly affect apoptosis, COX2, ER or PgR expression.

Conclusion: There is only modest evidence for a biological effect of celecoxib in primary breast cancer. However, the trend towards a reduction in Ki67 in ER-positive breast cancer warrants further investigations in a larger cohort of patients. 


\section{Introduction}

A number of studies over the past two decades have linked the use of non-steroidal antiinflammatory drugs (NSAIDs) and cancer incidence [1]. In particular work relating to NSAIDs in colorectal cancer has reported an inverse relationship between colon cancer incidence and regular use of NSAIDs [2-3]. Furthermore, randomised placebo-controlled double-blind trials have shown regression in colorectal polyp size after treatment with sulindac [4-5]. The data in relation to NSAID use and breast cancer incidence are conflicting. For instance a large cohort study of 89,528 registered nurses in the USA showed no association between regular use of asprin and the incidence of breast cancer [6]. By contrast, in a case control study, Harris et al [7] found a reduced risk of breast cancer associated with the use of any NSAID, three or more times a week for at least a year (RR 0.66). Subsequently a meta-analysis, involving 38 studies supported the inverse association between NSAID use and risk of breast cancer reporting a statistically significant reduction in breast cancer risk associated with use of any NSAID (RR 0.88) and similar associations for aspirin (RR 0.87) and ibuprofen (RR 0.79). No evidence of a dose-response relationship was found and some studies indicated that coxibs were also associated with a lower risk of breast cancer [8]. This large-scale meta-analysis is consistent with several smaller meta-analyses [9-12].

A chemopreventative effect of NSAIDs for breast cancer would be very important considering their excellent tolerability and inexpensiveness.

The main target of NSAID action is cyclooxgenase (COX), which plays an integral role in the catalysis of arachidonic acid to prostaglandin (PG). Two isoenzymes exist, COX-1, which is constitutively active and COX-2 which is expressed in response to certain 
stimuli such as tumour promoters, endotoxin, cytokines and hormones (reviewed by Davies et al [13]). COX-2 expression has been associated with features of aggressive breast cancer [14], including large tumour size, positive axillary lymph node metastases and HER-2 postive status [15]. Indirect evidence linking COX-2 to breast cancer has come from studies of tissue PGs, in which high PG levels are associated with poor disease-free and overall survival [16,17]. Most notably PGE2, the main catalytic product of COX-2, has been found in high concentrations in tumour cells [18] and clinically associated with enhanced metastatic potential and lack of estrogen (ER) and progesterone receptor (PgR) expression [19]. Compelling evidence from transgenic models has shown that development of breast tumours is enhanced by expression of COX-2 [20]. A chemopreventive effect of a specific COX-2 inhibitor celecoxib was demonstrated in DMBA-induced mammary tumour models in female rats resulting in a reduction in tumour incidence and tumour volume [21]. Whilst more recently the chemopreventive effects of celecoxib have been shown to be limited to hormonally responsive mammary carcinomas in the neu-induced retroviral rat model [22].

Expression of COX-2 in human solid cancers has also been associated with the neovasculature where significant correlations between COX-2 expression and tumour vascularization and microvessel density have been reported [23]. Of note animal models of angiogenesis have shown that celecoxib reduced both the number and length of sprouting capillaries in a dose dependent manner [24]. In addition to angiogenic effects, COX-2 expression has been shown to inhibit tumour apoptosis an effect negated in human prostate cancer cells by treatment with celecoxib [25].

More recently studies have implicated $\mathrm{COX}-2$ with the regulation of aromatase expression [26]. Numerous studies have shown that over $70 \%$ of breast tumours are steroid receptor positive and rely on estrogen stimulation for their growth [27]. In post 
menopausal women even small differences in serum concentrations of estradiol have been associated risk of breast cancer [28]. Plasma estrogens in postmenopausal women result from aromatase activity in peripheral tissues, particularly adipose. Many breast cancers also contain aromatase [29] suggesting that intratumoural aromatase may be important in breast cancer incidence and progression. There is strong evidence that the promoters that regulate aromatase gene transcription differ between normal and malignant breast tissue [30]. The promoters (exons 1.3 and II) regulating gene transcription in malignant tissue are controlled via cAMP which is known to be stimulated by PGE2 in breast tumour cells, suggesting that PGE2 may induce promoter switching (reviewed by Davies et al [13]). In support of this Bruggemeier's group demonstrated a strong positive correlation between COX-2 and aromatase in 23 human breast tumours using quantitative RT-PCR. Of note however, the highest levels of COX-2 expression were also associated with tumours showing evidence of vascular invasion [31].

Aromatase inhibitors are currently under investigation in chemoprevention but their systemic side effects such as enhanced bone re-absorption are a significant disadvantage [32]. Based on the above evidence suppression of COX-2 may provide a means of selectively suppressing estrogen levels in the breast and stimulation of estrogen dependent proliferation in ER+ breast cancer.

Hence there are several putative mechanism by which COX2 inhibitors might act to reduce breast cancer incidence but very limited direct evidence for their involvement in clinical material.

We therefore initiated a randomised controlled pre-surgical study of celecoxib in women with primary breast cancer during the two-week period prior to surgery; The primary 
purpose was to determine whether COX-2 inhibition led to antiproliferative, proapoptotic and or antiestrogenic effects on molecular markers of biological response.

\section{Materials and Methods}

\section{Study}

The study design was a randomised phase II trial of celecoxib versus no treatment $(2: 1)$. The drug dose used was 400mg orally twice daily based on studies using celecoxib in Familial Adenomatosis Polyposis [33]. The target study size was 40 patients. Using the SD of the $\log (\mathrm{Ki67})$ score from a variability study of Ki67, it was estimated that there was an $80 \%$ probability of observing a significant $\mathrm{Ki} 67$ suppression when the true reduction in Ki67 was $\geq 50 \%$, if complete data on 30 volunteers was derived [34,35]. The drug was given in the two-week period between diagnosis and surgical treatment. Patients were eligible for the study if they were postmenopausal, 50-80 years of age, had a clinical diagnosis of stage I or II [American Joint Committee on Cancer (http://www.cancerstaging.org/)], histologically confirmed, primary breast cancer and with a tumour size sufficient to provide a core biopsy, ECOG performance status 0,1 or 2 , normal full blood count, normal urea and electrolytes and liver function tests. Patients were excluded if they had recurrent disease, metastases, renal or hepatic impairment, active inflammatory bowel disease or peptic ulceration, current use of NSAIDs including aspirin in the 4 weeks prior to study entry, or use of HRT or oral contraceptives during or 4 weeks prior to study entry.

The Royal Marsden Hospital Research and Ethics Committee approved the study and each patient gave written informed consent.

\section{Biopsy Method}


Before the start of the study medication, a core biopsy of the primary breast tumour was obtained using a 14-gauge needle. Ultrasound guidance was used to obtain material from smaller tumours to aid accuracy. At surgery a sample of excised tumour was obtained from the operative specimen. Both specimens were immediately fixed in $10 \%$ normal buffered formalin and embedded in paraffin.

\section{Analysis Methods}

Measurement of cell proliferation was by immunohistochemical assay using the MIB1 mouse monoclonal antibody to Ki67 [34]. Measurement of apoptosis was by terminal deoxynucleotidyl transferase biotin-dutp nick end labeling technique (TUNEL). The apoptotic index was expressed as a percentage of the number of cells displaying apoptotic bodies [35]. Tumour cells/section were counted for Ki67 (1000 cells) and apoptotic index (3000 cells) based on precision data published previously [36]. ER expression was demonstrated with the Novacastra antibody 6F11 [37] and PgR with the Novacastra antibody NCL-PgR clone 1A6 [34]. Samples were also assessed for expression of COX-2 [38] using the antibody PG-27B (Oxford Biomedical Research Inc), and CD31 (DAKO) [38]. ER, PgR and COX2 expression were assessed semi-quantitatively using an H-score as follows: $(\%$ of cells intensity $1 \times 1)+(\%$ of cells intensity $2 \times 2)+(\%$ of cells intensity $3 \times 3)$ providing a score range of 0 to 300 . Samples were considered positive for either receptor if the score exceeded 1\%. CD31 expression was determined using a Chalkey count [39]. Two individual observers assessed scoring and a consensus was reached for each biomarker.

\section{Statistical methods}

Descriptive statistics were expressed as geometric means. Values at baseline and at 2 weeks were expressed as geometric mean proportions of the baseline and transformed 
into percentage changes (a negative change denoting a reduction). Comparisons between groups were conducted using the Mann Whitney test with a two-sided 5\% significance.

\section{Results}

Recruitment to the trial was compromised by competing studies and a decision to terminate recruitment after 25 patients was taken blind of any study results. In 2 cases from the treatment arm no malignant tissue was present in the pre-treatment sample leaving 23 paired sets of data, 14 on the treatment arm and 9 on no-treatment arm. Paired treatment and post-treatment data on Ki67 and CD31 was available on all 23 patients. The clinicopathological variables of the 23 patients recruited are shown according to randomisation arm in Table 1. The mean age of the patients in the celecoxib arm was 68 years and in the no treatment arm 71 years. The median (range) tumour sizes were $19.5 \mathrm{~mm}(10-60)$ and 20mm (11-29), respectively. Fifty percent and 67\% respectively were grade 3 . The majority of tumours in both groups were lymph node negative and did not exhibit vascular invasion. At baseline only 3 patients were ER-negative; 1 in the celecoxib arm and 2 in the no treatment. Sixteen patients were PgR-positive (11 and 5, respectively); 2 patients were HER-2 positive (1 in each arm).

The change in each of the parameters and the statistical comparisons are summarised in Table 2 .

The change in Ki67 is shown for individual patients according to treatment arm in Figure 1A and B with the ER-negative patients highlighted. The geometric mean change in Ki67 relative to baseline in the celecoxib arm was $-16.6 \%(95 \% \mathrm{CI}-31.4$ to $+1.4 \% \mathrm{p}=0.056)$. Exclusion of the ER-negative patient gave a geometric mean change of $-18.1 \%$ (95\% CI 33.5 to $+0.9 \% \mathrm{p}=0.055)$. The change in the no-treatment group was $-8.1 \%(95 \% \mathrm{CI}-23.2$ to 
$+10.1 \% \mathrm{p}=0.24)$. There was no statistically significant difference in the change between the 2 groups irrespective of the inclusion or not of ER-negative patients.

The change in apoptotic index is shown for individual patients according to treatment arm in Figure 2A and B with the ER negative patients highlighted. Insufficient cells were present in the pre-treatment sample for an estimation of apoptotic index for one patient on the celecoxib arm. There was no significant change in the index with geometric mean changes of $+4.0 \%(95 \% \mathrm{CI}-23.4$ to $+41.0 \%, \mathrm{p}=1.00)$ and $+8.7 \%(95 \% \mathrm{CI}-26.1$ to $+59.7 \%$, $p=0.29)$ in the celecoxib and no-treatment arms respectively.

The effect of treatment on the expression of ER and PgR for those patients showing pretreatment positive status of the respective receptor is shown in Figures 3 and 4 respectively. Level of expression and positive/negative status was stable for both receptors during treatment.

CD31 levels increased in 13 of the 14 tumours during celecoxib treatment showing an overall statistically significant increase in expression of $22.2 \%(95 \% \mathrm{CI}+4.8$ to $+42.6 \%$, $p=0.009$; Fig 5). In contrast CD31 expression increased in 4/9 control patients but the difference in change between the 2 arms was not statistically significant. There was no significant effect of treatment on the expression of COX-2 (Fig 6).

\section{Discussion}

This study aimed in part to determine whether suppression of COX-2 activity with the selective COX-2 inhibitor celecoxib, would lead to suppression of Ki67 consistent with this providing tissue specific suppression of aromatase activity and an alternative to systemic aromatase inhibition. The target study size was 40 patients but difficulties with 
competing studies led to its termination after 25 patients. This curtailment of the study inevitably led to loss of statistical power but the data analyzed allowed instructive comparisons with earlier presurgical studies of aromatase inhibitors to be made [40-43]. In these latter studies large reductions in expression of biomarkers in the order of $80 \%$ were evident for $\mathrm{Ki} 67$ and $\mathrm{PgR}$ as early as 2 weeks post treatment. It is clear from our data that the changes with celecoxib were much more modest than this for Ki67 and there was no indication of a reduction in $\mathrm{PgR}$.

Our hypothesis was based on the association between COX-2, PGE2 and aromatase activity. The inhibition of COX-2, should lead to a decrease in PGE2 and cAMP levels. If the hypothesis was correct this would lead to reduced aromatase activity and hence estrogen biosynthesis/signalling, resulting in a decrease in tumour proliferation (Ki67) and other markers of a functional estrogen signalling pathway (eg PgR) in ER+ tumours [42]. Ki67 and PgR are some of the most studied and robust molecular markers in relation to neoadjuvant endocrine therapy. We have previously shown that the aromatase inhibitors vorozole and anastrozole $[41,42]$ led to decreases in Ki67 of $58 \%$ and $75 \%$ respectively in the first 2 weeks of treatment accompanied by substantial falls in PgR.

As expected analysis of the no treatment arm showed no significant change in Ki67 or apoptosis during the course of the study in keeping with previous observations $[44,45]$

Our data revealed that there was a non-significant trend towards a reduced level of Ki67 with the celecoxib arm c. $20 \%$. Ki67 at baseline showed no association with response to celecoxib. However, high Ki67 levels were associated with higher tumour grade in both the no treatment and celecoxib arms. As noted earlier, reduction in Ki67 was less pronounced than expected when compared with previous studies of vorozole or 
anastrazole $[41,42]$. The lack of change in PgR expression suggests that celecoxib had little effect on oestrogen dependent processes in this setting and that any change in Ki67 was probably not dependent on reduced oestrogen signalling. Although the change in Ki67 in response to celecoxib was small, and maybe due to chance it should be noted that we found a change of only $24 \%$ with raloxifene, an agent that has subsequently been shown to have chemopreventative activity similar to tamoxifen [44].

The lack of a statistically significant effect on Ki67 in response to 2-weeks treatment with celecoxib may be due to a number of factors. For instance this study was powered to detect a large effect ( $\triangle 50 \%)$ and any effect of COX-2 inhibition appears to be smaller than this and would require larger patient numbers to detect with confidence. The trend towards a reduction in Ki67 after celecoxib merits further investigation given the potenial importance of confirmation; particularly in view of the fact that previous studies addressing the role of celecoxib on Ki67 in ER+ DCIS [45] and in women with early stage breast cancer [46] have provided conflicting results. For instance in the recent study by Bundred et al, [45] celecoxib had no significant effect on Ki67 when given as a single agent whilst in the Tfayli et al [46] study a significant increase in Ki67 $(\mathrm{p}<0.009)$ in response to treatment was noted. However, this study had no placebo arm for comparison. It is also possible that unlike aromatase inhibitors, the antiproliferative effects of celecoxib may only manifest themselves after a prolonged course of treatment. Duration of treatment was based on that seen to be effective in terms of reduced proliferation caused by aromatase inhibitors in this setting: any effects of celecoxib as a result of aromatase suppression would therefore be expected to be detectable over that time period. However, other putative effects of $\mathrm{COX} 2$ inhibition such as angiogenesis may require longer than 2 weeks to become evident. 
While the data do not support a major site specific reduction in oestrogen synthesis, a recent study assessing the relationship between current NSAID use and endogenous oestradiol levels in 260 postmenopausal women, showed that age-adjusted and body mass index-adjusted geometic mean serum oestradiol levels among NSAIDs users was significantly lower compared to non-users [47]. This supports the wider hypothesis that NSAIDs block estrogen signalling and provides a mechanism through which NSAIDs might exert a protective effect against breast cancer.

The available evidence suggests that blockade of COX-2 may provide clinical benefit by increasing apoptosis rather than lowering proliferation, as shown in pre-clinical models [25]. However, no significant changes were seen in the level of apoptosis in the celecoxib treated patients. Again we cannot exclude an effect from longer treatment duration.

As discussed previously COX-2 expression has also been strongly associated with neovasculariztion in solid tumours [23]. Thus an alternate hypothesis could be that inhibition of COX-2 may result in reductions in tumour vasculature [24] affecting tumour growth. However, our assessment of the effect of celecoxib versus placebo on neovasculatization showed no significant difference between the two arms but there was a statistically significant increase in CD31 expression in the pre-treatment versus the posttreatment samples in the celecoxib arm. The data on CD31 should be viewed with caution as the comparison is made between different types of samples, core biopsy versus the excision biopsy, and vasularity may not be well represented in cores.

Any effect of celecoxib in breast cancer may also be dependent not only on the level of COX-2 expression. The preclinical and clinical evidence suggests that COX-2 over expression is most marked in tumours that are of a poor prognosis $[19,20]$. The link with 
COX-2 and angiogenesis may be indicative that patients with metastatic disease, or with large high grade, node positive disease and in particular HER-2 positive patients may benefit from celecoxib. The relatively favourable prognostic group studied here may therefore also account in part, for an absence of a demonstrable COX-2 inhibitory effect. Similarly the selective effectiveness of celecoxib may be obscured by the procarcinogenic contributions of constitutive COX-1. Preclinical data suggest expression of COX-1 may have implications for the effectiveness of selective COX2 inhibitors in tumours where COX-2 overexpression is not particularly prevalent $(\underline{48})$.

The strengths of the study reported here include its inclusion of a control no-treatment arm, its randomisation, rigorous pre-recruitment clinical assessment and centralised conduct of the biomarker analyses in a highly experienced laboratory. The lower than intended number of recruits is a substantial weakness.

In summary these data suggest that celecoxib does not provide site-specific oestrogen deprivation in ER+ primary breast cancers when compared to the current third generation aromatase inhibitors. The trend to a reduction in proliferation is however, worthy of further investigation since modest reductions have been associated with substantial chemopreventive effects with raloxifene. The cardiovascular toxicity [49] noted with long-term use of COX-2 inhibitors would however, remain a concern for this widespread chemopreventive application and hence necessitate refocusing COX-directed cancer prevention strategies to avoid this danger

\section{Acknowledgements}


We are grateful to the patients who participated in this trial and thank Breakthrough Breast Cancer and The Mary-Jean Mitchell Green Foundation for generous funding. We also acknowledge NHS funding to the NIHR Biomedical Research Centre.

\section{References}

1. Mehta RG, Moon RC (1991) Characterization of effective chemo preventive agents in mammary gland in vitro using an initiation-promotion protocol. Anticancer Res 11: 593596.

2. Thun MJ, Namboodiri MM, Heath CW, Jr (1991) Aspirin use and reduced risk of fatal colon cancer. N Engl J Med 325: 1593-6

3. Rosenberg L, Palmer JR, Zauber AG, Warshauer ME, Stolley PD, Shapiro S (1991) A hypothesis: nonsteroidal anti-inflammatory drugs reduce the incidence of large-bowel cancer. J Natl Cancer Inst 83: 355-358

4. Nugent KP, Farmer KC, Spigelman AD, Williams CB, Phillips RK (1993) Randomized controlled trial of the effect of sulindac on duodenal and rectal polyposis and cell proliferation in patients with familial adenomatous polyposis. Br J Surg 80: 1618-1619 5. Giardiello FM, Hamilton SR, Krush AJ, et al (1993) Treatment of colonic and rectal adenomas with sulindac in familial adenomatous polyposis. N Engl J Med 328: $1313-1316$

6. Egan KM, Stampfer MJ, Giovannucci E, Rosner BA, Colditz GA (1996) Prospective study of regular aspirin use and the risk of breast cancer. J Natl Cancer Inst 88:988-993.

7. Harris RE, Namboodiri KK, Farrar WB (1996) Nonsteroidal antiinflammatory drugs and breast cancer. Epidemiology 7: 203-5

8. Takkouche B, Regueira-Méndez C, Etminan M (2008) Breast cancer and use of nonsteroidal anti-inflammatory drugs: a meta-analysis. J Natl Cancer Inst 100:1439-1447. 
9. Bosetti C, Gallus S, La Vecchia C (2006) Aspirin and cancer risk: an updated quantitative review to 2005. Cancer Causes Control 17:871-888

10. Gonzalez-Perez A, Garcia Rodriguez LA, Lopez-Ridaura R (2003) Effects of nonsteroidal anti-inflammatory drugs on cancer sites other than the colon and rectum: a metaanalysis. BMC Cancer 3:28

11. Khuder SA, Mutgi AB. (2001) Breast cancer and NSAID use: a meta-analysis. Br J Cancer 84:1188-1192

12. Mangiapane S, Blettner M, Schlattmann P. (2008) Aspirin use and breast cancer risk: a meta-analysis and meta-regression of observational studies from 2001 to 2005. Pharmacoepidemiol Drug Saf 17:115-124

13. G. Davies, L.-A. Martin, N. Sacks and M. Dowsett (2002) Cyclooxygenase (COX2), aromatase and breast cancer: a possible role for COX-2 inhibitors in breast cancer chemoprevention. Annals of Oncology 13: 669-678

14. Brueggemeier RW, Quinn AL, Parrett ML, Joarder FS, Harris RE, Robertson FM (1999) Correlation of aromatase and cyclooxygenase gene expression in human breast cancer specimens. Cancer Lett 140:27-35

15. Subbaramaiah K, Norton L, Gerald W et al (1999) Increased expression of cyclooxygenase-2 in HER-2-overexpressing human breast cancer cells. NCI $7^{\text {th }}$ SPORE Investigators Workshop

16. Bennett A (1986) The production of prostanoids in human cancers, and their implications for tumor progression. Prog Lipid Res 25: 539-542

17. Rolland PH, Martin PM, Jacquemier J, Rolland AM, Toga M (1980) Prostaglandin in human breast cancer: Evidence suggesting that an elevated prostaglandin production is a marker of high metastatic potential for neoplastic cells. J Natl Cancer Inst 64:1061-1070

18. Schrey MP, Patel KV (1995) Prostaglandin E2 production and metabolism in human breast cancer cells and breast fibroblasts. Regulation by inflammatory mediators. Br J Cancer 72: 1412-1419 
19. Witton CJ, Hawe SJ, Cooke TG, Bartlett JM (2004) Cyclooxygenase 2(COX2) expression is associated with poor outcome in ER-negative, but not ER-positive breast cancer. Histopathology 45: 47-54

20. Liu CH, Chang SH, Narko K, et al (2001) Overexpression of cyclooxygenase-2 is sufficient to induce tumorigenesis in transgenic mice. J Biol Chem 276: 18563-18569

21. Harris RE, Alshafie GA, Abou-Issa H, Seibert K (2000) Chemoprevention of breast cancer in rats by celecoxib, a cyclooxygenase 2 inhibitor. Cancer Res 60: 2101-2103

22. Woditschka S, Haag JD, Mau B, Lubet RA, Gould MN (2008). The chemopreventive effects of celecoxib are limited to hormonally responsive mammary carcinomas in the neu-induced retroviral rat model. Breast Cancer Res 15 10:R18

23. Uefuji K, Ichikura T, Mochizuki H (2000) Cyclooxygenase-2 expression is related to prostaglandin biosynthesis and angiogenesis in human gastric cancer. Clin Cancer Res 6: $135-138$

24. Masferrer JL, Leahy KM, Koki AT, et al (2000) Antiangiogenic and antitumor activities of cyclooxygenase-2 inhibitors. Cancer Res 60:1306-1311

25. Hsu AL, Ching TT, Wang DS, Song X, Rangnekar VM, Chen CS (2000) The cyclooxygenase-2 inhibitor celecoxib induces apoptosis by blocking Akt activation in human prostate cancer cells independently of Bcl-2. J Biol Chem 275: 11397-11403

26. Brueggemeier RW, Su B, Sugimoto Y, Díaz-Cruz ES, Davis DD (2007).Aromatase and COX in breast cancer: enzyme inhibitors and beyond. J Steroid Biochem Mol Biol 106: $16-23$

27. Ali S, Coombes RC (2002). Endocrine-responsive breast cancer and strategies for combating resistance. Nat Rev Cancer 2: 101-112

28. Thomas HV, Key TJ, Allen DS, et al (1997) A prospective study of endogenous serum hormone concentrations and breast cancer risk in premenopausal women on the island of Guernsey. Br J Cancer 75 :1075-1079 
29. Reed MJ, Owen AM, Lai LC, et al (1989) In situ oestrone synthesis in normal breast and breast tumour tissues: effect of treatment with 4-hydroxyandrostenedione. Int $\mathrm{J}$ Cancer $44: 233-237$

30. Zhou C, Zhou D, Esteban J, et al (1996) Aromatase gene expression and its exon I usage in human breast tumors. Detection of aromatase messenger RNA by reverse transcription-polymerase chain reaction. J Steroid Biochem Mol Biol 59: 163-171

31. Brueggemeier RW, Quinn AL, Parrett ML, Joarder FS, Harris RE, Robertson FM (1999) Correlation of aromatase and cyclooxygenase gene expression in human breast cancer specimens. Cancer Lett 140: 27-35

32. Cuzick J (2008) Chemoprevention of breast cancer. Breast Cancer 15: 10-16

33. Arber N, Eagle CJ, Spicak J, Rácz I, Dite P, Hajer J, Zavoral M, Lechuga MJ, Gerletti P, Tang J, Rosenstein RB, Macdonald K, Bhadra P, Fowler R, Wittes J, Zauber AG, Solomon SD, Levin B; PreSAP Trial Investigators (2006) Celecoxib for the prevention of colorectal adenomatous polyps. N Engl J Med 355: 885-895

34. Harper-Wynne C, Ross G, Sacks N, et al (2002) Effects of the aromatase inhibitor letrozole on normal breast epithelial cell proliferation and metabolic indices in postmenopausal women: a pilot study for breast cancer prevention. Cancer Epidemiol Biomarkers Prev 11:614-621

35. Ellis PA, Smith IE, Detre S, Burton S, Salter J, A'hern R, Walsh G, Johnston SR, Dowsett M (1998) Reduced apoptosis and proliferation and increased Bcl-2 in residual breast cancer following preoperative chemotherapy. Breast Cancer Res Treat 48: 107-116

36. Detre S, Salter J, Barnes DM, Riddler S, Hills M, Johnston SR, Gillett C, A'Hern R, Dowsett M (1999). Time-related effects of estrogen withdrawal on proliferation- and cell death related events in MCF7 xenografts. Int J. Cancer 81: 309-313

37. Saccani Jotti, G, Johnston SR, Salter J, Detre S, Dowsett M (1994). Comparison of new immunohistochemical assay for estrogen receptor in paraffin wax embedded breast 
carcinoma tissue with quantitative enzyme immunoassay. J. Cin Pathol (Lond) 47: 900905

38. Davies G, Salter J, Hills M, Martin LA, Sacks N, Dowsett M (2003) Correlation between cyclooxygenase-2 expression and angiogenesis in human breast cancer. Clin Cancer Res 9: 2651-2666

39. Fox SB, Leek RD, Weekes MP, Whitehouse RM, Gatter KC, Harris AL (1995) Quantitation and prognostic value of breast cancer angiogenesis: comparison of microvessel density, Chalkley count, and computer image analysis. J Pathol 177: 275-283 40. Eiermann W, Paepke S, Appfelstaedt J, et al (2001) Preoperative treatment of postmenopausal breast cancer patients with letrozole: A randomized double-blind multicenter study. Ann Oncol 12: 1527-1532

41. Harper-Wynne CL, Sacks NP, Shenton K, et al (2002) Comparison of the systemic and intratumoral effects of tamoxifen and the aromatase inhibitor vorozole in postmenopausal patients with primary breast cancer. J Clin Oncol 20:1026-1035

42. Smith IE, Dowsett M, Ebbs SR, et al (2005) Neoadjuvant treatment of postmenopausal breast cancer with anastrozole, tamoxifen, or both in combination: the Immediate Preoperative Anastrozole, Tamoxifen, or Combined with Tamoxifen (IMPACT) multicenter double-blind randomized trial. J Clin Oncol 23:5108-5116.

43. Dowsett M, Ebbs SR, Dixon JM, et al (2005) Biomarker changes during neoadjuvant anastrozole, tamoxifen, or the combination: influence of hormonal status and HER-2 in breast cancer--a study from the IMPACT trialists. J Clin Oncol 223:2477-92

44. Dowsett M, Bundred NJ, Decensi A, et al (2001) Effect of raloxifene on breast cancer cell Ki67 and apoptosis: a double-blind, placebo-controlled, randomized clinical trial in postmenopausal patients. Cancer Epidemiol Biomarkers Prev 10:961-966 
45. Bundred NJ, Cramer A, Morris J, et al (2010) Cyclooxygenase-2 inhibition does not improve the reduction of ductal carcinoma in situ proliferation with aromatase therapy: results of the ERISAC randomized placebo controlled trial. Clin Can Res 16:1605-1612 46. Tfayli A, Yang J, Kojouri K, Kesserwan C, Jafari M, Ozer H (2008) Neoadjuvant therapy with celecoxib in women with early stage breast cancer. Neoplasma 55:122-126 47. Hudson AG, Gierach GL, Modugno F, et al (2008) Nonsteroidal anti-inflammatory drug use and serum total estradiol in postmenopausal women. Cancer Epidemiol Biomarkers Prev 17:680-687

48. Tiano HF, Loftin CD, Akunda J, et al (2002) Deficiency of either cyclooxygenase (COX)-1 or COX-2 alters epidermal differentiation and reduces mouse skin tumorigenesis. Cancer Res 62:3395-3401

49. Mukherjee D, Nissen SE, Topol EJ (2001) Risk of cardiovascular events associated with selective COX-2 inhibitors. JAMA 286: 954-959 


\section{Figure Legends}

Figure 1 Changes in expression of Ki67 were assessed by immunohistochemistry. Tumour biopsies were stained pre and post 2 -weeks treatment. Values from individual patients are expressed as mean H-score. A. celecoxib $(n=14)$ and B. No treatment $(n=9)$.

Figure 2 Changes in apoptosis were assessed by TUNEL. Tumour biopsies were screened pre and post 2-weeks treatment. Values from individual patients are expressed as mean apoptotic score. A. celecoxib $(n=14)$ and B. No treatment $(n=9)$.

Figure 3 Alterations in expression of ER were assessed by immunohistochemistry. Tumour biopsies were stained pre and post 2-weeks treatment. Values from individual ER+ patients are expressed as mean H-score. A. celecoxib $(n=13)$ and B. Placebo $(n=7)$.

Figure 4 Alterations in expression of PgR were assessed by immunohistochemistry. Tumour biopsies were stained pre and post 2-weeks treatment. Values from individual $\mathrm{PgR}+$ patients are expressed as mean $\mathrm{H}$-score. A. celecoxib $(n=11)$ and B. Placebo $(n=5)$.

Figure 5 The effect of celecoxib on tumour angiogenesis was assessed by measuring alterations in expression of CD31. Tumour biopsys were stained pre and post 2-weeks treatment and evaluated using the Chakley Score. A. celecoxib $(n=14)$ and B. Placebo $(n=9)$

Figure 6 The effect of celecoxib on COX-2 expression was assessed by immunohistochemistry. Tumour biopsies were stained pre and post 2-weeks treatment. 
Values from individual patients are expressed as mean H-score. A. celecoxib $(n=10)$ and B. Placebo $(n=8)$.

Table 1. Clinicopathological variables of patients in Celecoxib and no treatment arm of 2 week presurgical study

\begin{tabular}{|l|l|l|}
\hline $\begin{array}{l}\text { Baseline characteristics of } \\
\text { patients }\end{array}$ & No treatment & Celecoxib \\
\hline No Patients & 9 & 14 \\
\hline Mean age (yr) (range) & $71(59-89)$ & $68(53-86)$ \\
\hline $\begin{array}{l}\text { Mean tumour size (range } \\
\text { mm) }\end{array}$ & $20(11-29)$ & $19.5(10-60)$ \\
\hline Grade II & $3(33 \%)$ & $7(50 \%)$ \\
\hline \multicolumn{1}{|c|}{ III } & $6(67 \%)$ & $7(50 \%)$ \\
\hline ER-positive & $7(77 \%)$ & $13(92 \%)$ \\
\hline ER negative & $2(22 \%)$ & $1 \quad(7 \%)$ \\
\hline PgR positive & $5(56 \%)$ & $11(79 \%)$ \\
\hline HER2 positive & $1(11 \%)$ & $1 \quad(7 \%)$ \\
\hline
\end{tabular}

Table 2: Geometric mean percentage change in biomarker expression from baseline at 2 weeks

\begin{tabular}{|l|l|l|l|l|l|l|l|}
\hline & Celecoxib & & $\begin{array}{l}\text { P } \\
\text { value }\end{array}$ & $\begin{array}{l}\text { No } \\
\text { Treat. }\end{array}$ & $\begin{array}{l}\mathbf{9 5 \%} \\
\text { CI }\end{array}$ & $\begin{array}{l}\text { P } \\
\text { value }\end{array}$ & $\begin{array}{l}\text { Palue } \\
\text { value }\end{array}$ \\
\hline & $\begin{array}{l}\text { Mean \% } \\
\text { change }\end{array}$ & $\mathbf{9 5 \% ~ C I ~}$ & & $\begin{array}{l}\text { Mean } \\
\%\end{array}$ & & & \\
\hline
\end{tabular}




\begin{tabular}{|l|l|l|l|l|l|l|l|}
\hline & & & & change & & \\
\hline Ki67 & -16.6 & $\begin{array}{l}-31.4 \text { to } \\
+1.4\end{array}$ & 0.056 & -8.1 & $\begin{array}{l}-23.2 \text { to } \\
+10.1\end{array}$ & 0.24 & 0.45 \\
\hline CD31 & +22.2 & $\begin{array}{l}+4.8 \text { to } \\
+42.6\end{array}$ & 0.009 & +1.2 & $\begin{array}{l}-28.2 \text { to } \\
-42.8\end{array}$ & 1.00 & 0.58 \\
\hline Apoptosis & +4 & $\begin{array}{l}-23.4 \text { to } \\
+41.0\end{array}$ & 1.00 & +8.7 & $\begin{array}{l}-26.1 \text { to } \\
+59.7\end{array}$ & 0.29 & 0.61 \\
\hline ER & -5.4 & $\begin{array}{l}-17.2 \text { to } \\
+8.1\end{array}$ & 0.11 & +15.5 & $\begin{array}{l}-11.2 \text { to } \\
+50.2\end{array}$ & 0.83 & 0.58 \\
\hline PgR & -1.8 & $\begin{array}{l}-23.1 \text { to } \\
+25.6\end{array}$ & 0.35 & +8.4 & $\begin{array}{l}-2.3 \text { to } \\
+20.2\end{array}$ & NT* & 0.18 \\
\hline COX-2 & +69.7 & $\begin{array}{l}-35.3 \text { to } \\
+342.3\end{array}$ & 0.54 & +49.5 & $\begin{array}{l}-63 \text { to }+ \\
504.4\end{array}$ & 0.36 & 0.96 \\
\hline
\end{tabular}

* Not Tested, too few observations to achieve statistical significance 
Click here to download Figure: Cox2 figsii.ppt

Figure 1

A

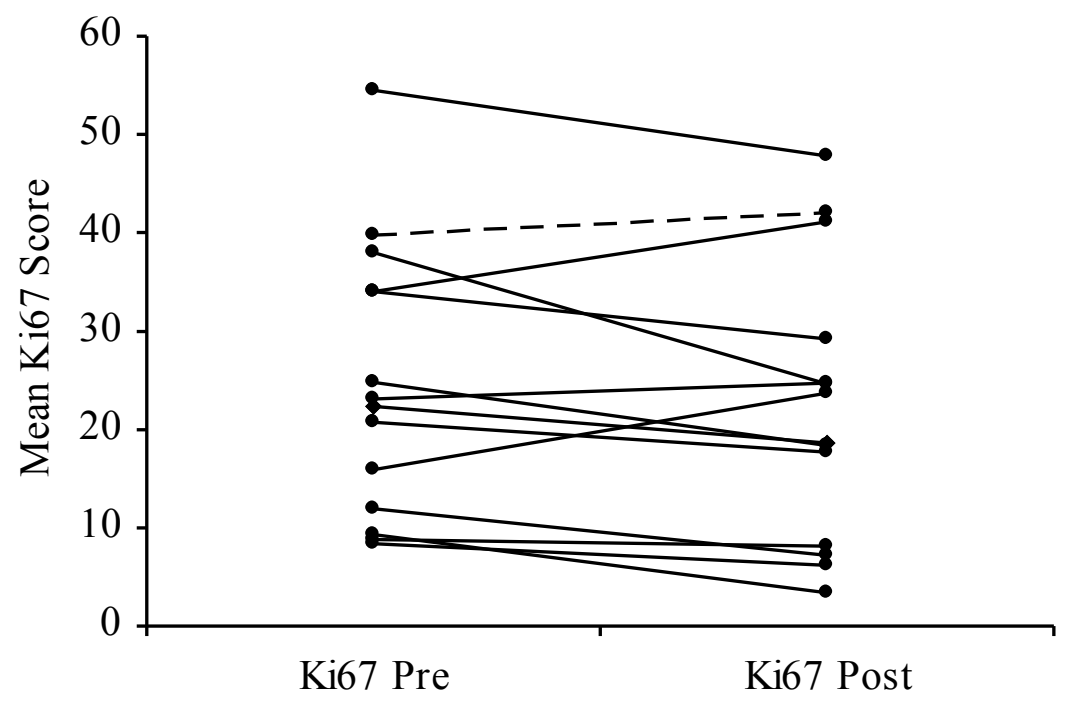

B

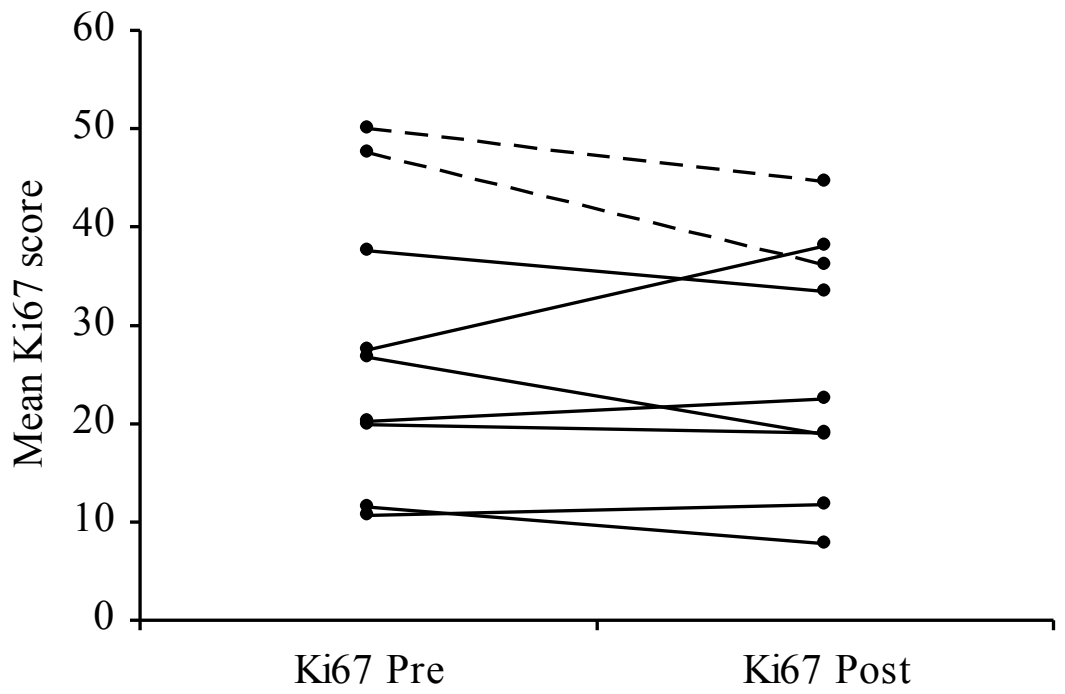


Figure 2

A

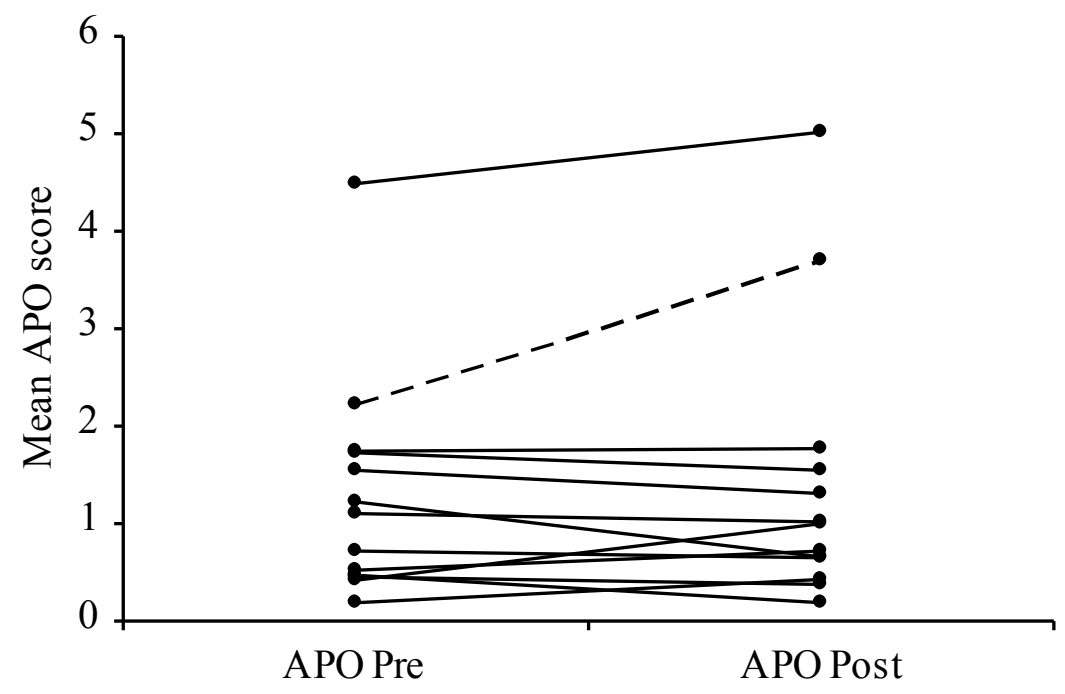

B

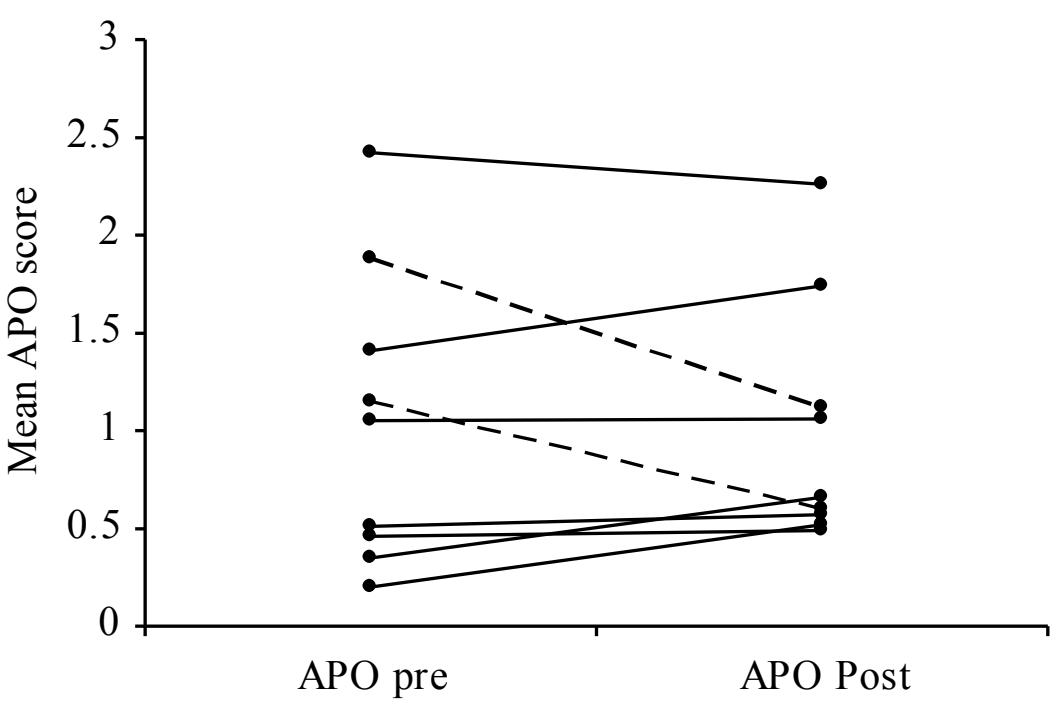


Figure 3

A

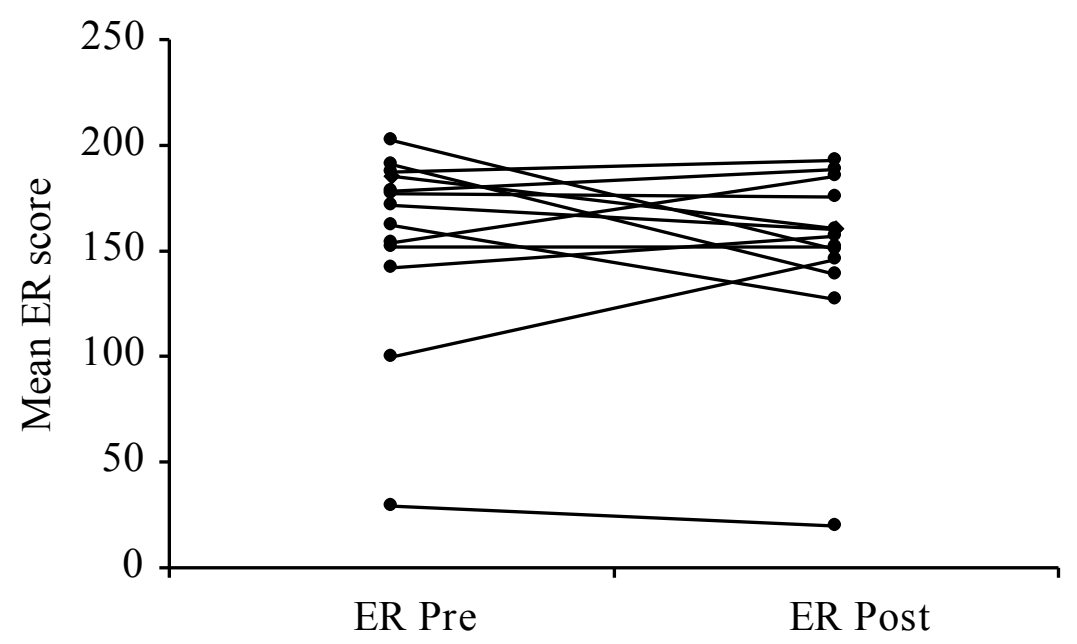

B

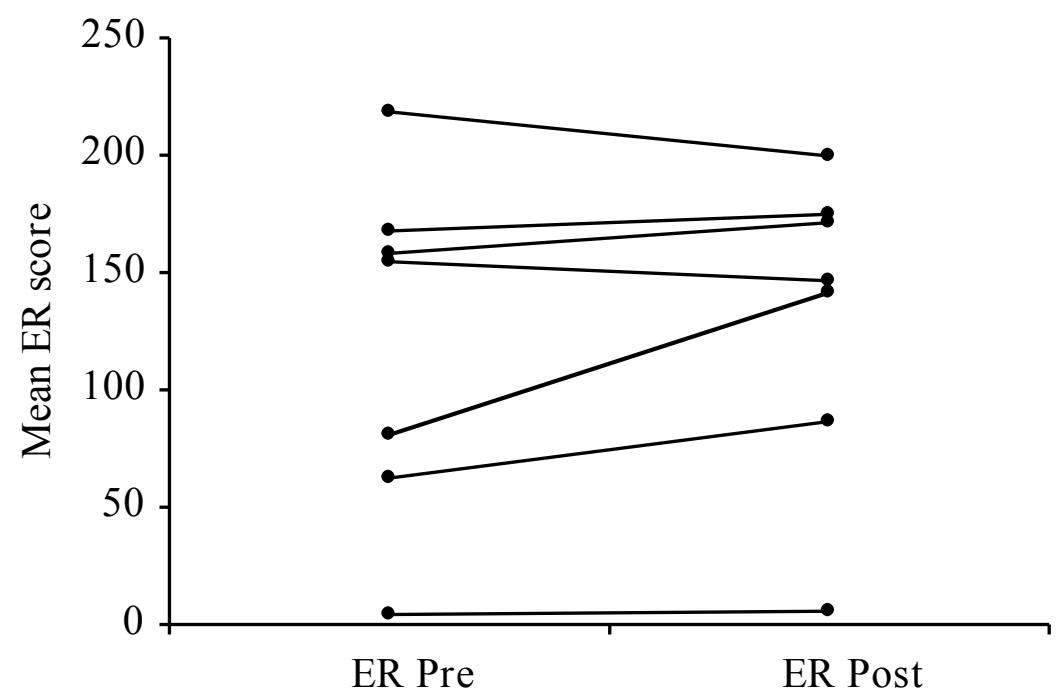


Figure 4

A
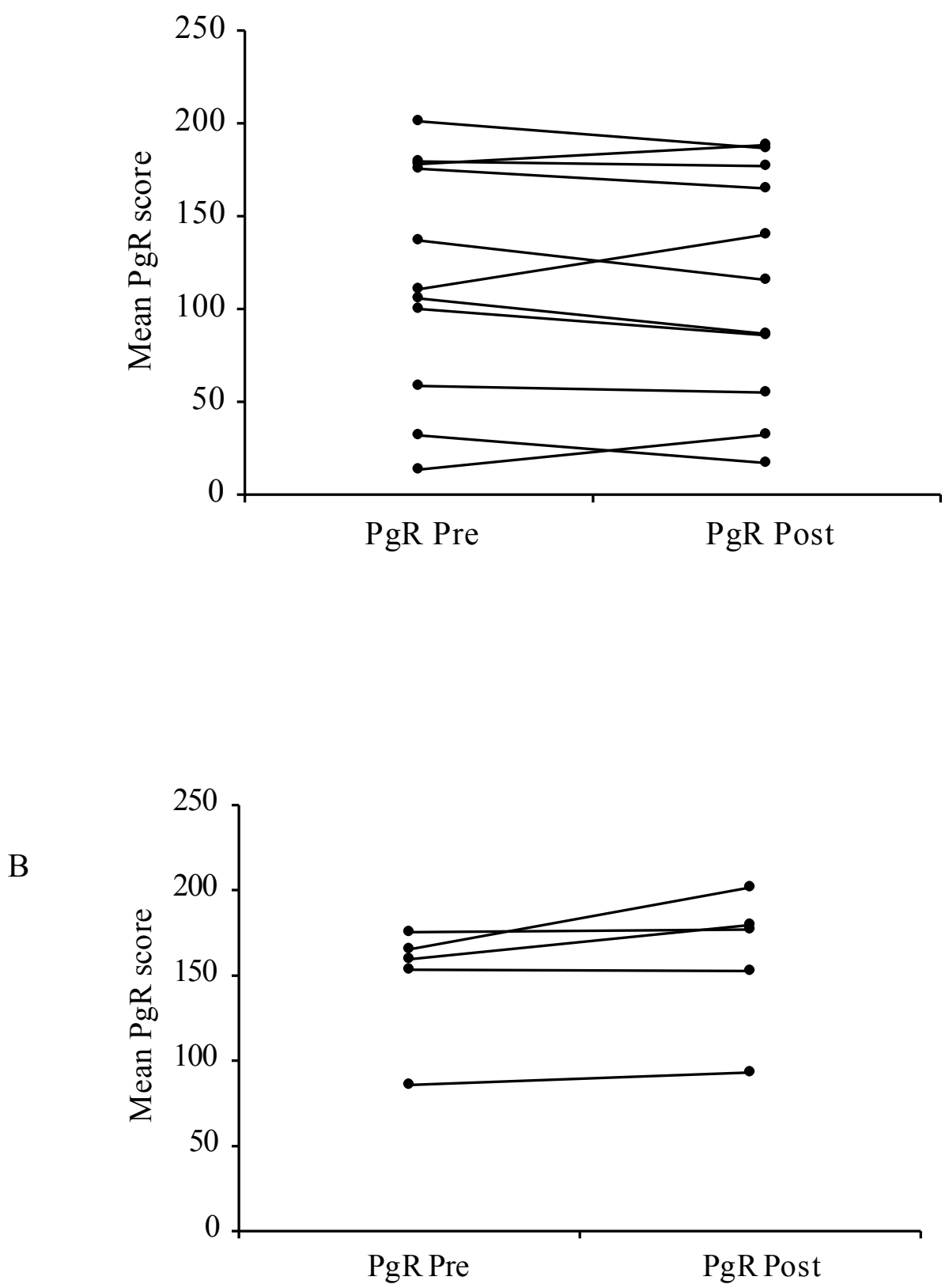
Figure 5

A

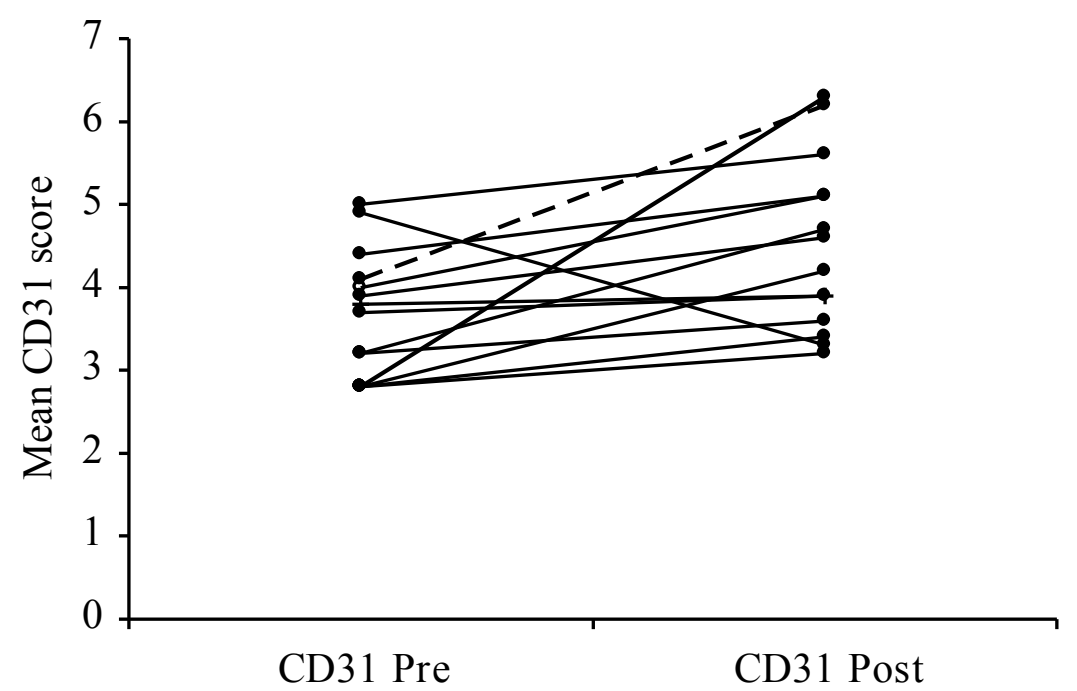

B

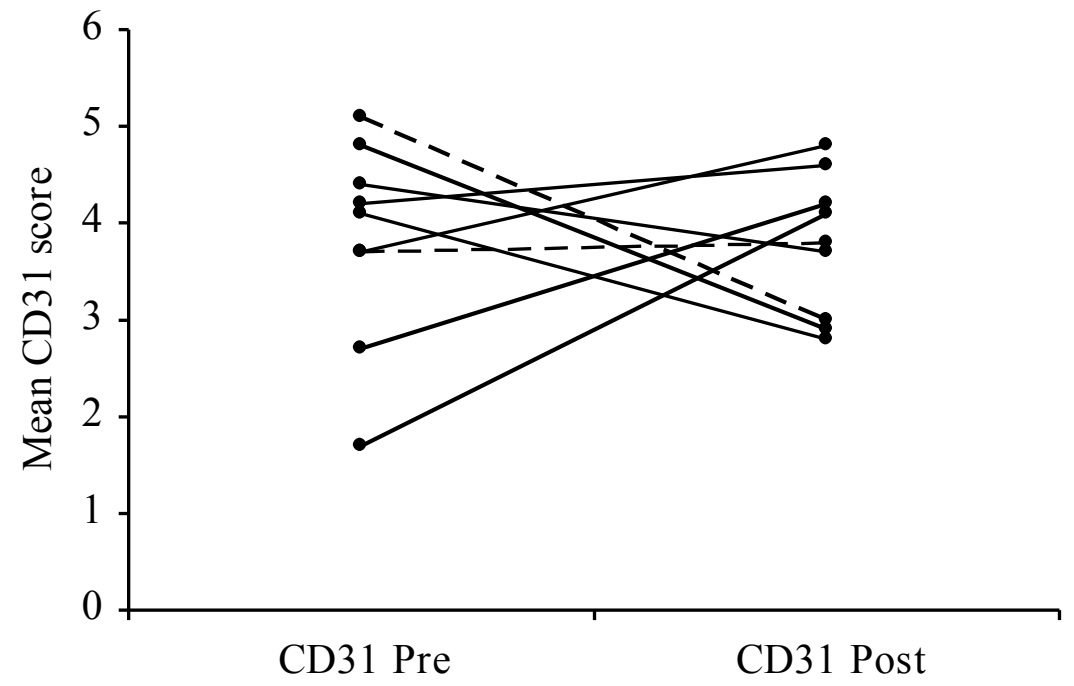

